\title{
Cyclin D3 Immunoreactivity in Gastrointestinal Stromal Tumors Is Independent of Cyclin D3 Gene Amplification and Is Associated with Nuclear p27 Accumulation
}

\author{
Giancarlo Pruneri, M.D., Giovanni Mazzarol, M.D., Sonia Fabris, B.Sc., Barbara Del Curto, B.Sc., \\ Francesco Bertolini, M.D., Ph.D., Antonino Neri, M.D., Giuseppe Viale, M.D. \\ Divisions of Pathology and Laboratory Medicine (GP, GM, BDC, GV) and Hemato-Oncology (FB), \\ European Institute of Oncology and University of Milan, School of Medicine; and Laboratory of \\ Experimental Hematology and Molecular Genetic (SF, AN), Ospedale Maggiore, Istituto di Ricovero e Cura \\ a Carattere Scientifico (IRCCS), Milan, Italy
}

An abnormal expression of cyclin D3, a key regulator of the cell cycle, has been documented in a variety of human malignancies, and the cyclin D3 gene, mapping to $6 \mathrm{p} 21$, may be deregulated in human tumors as a result of the $t(6 ; 14)(p 21.1 ; q 32.3)$ translocation or gene amplification. In the current study, we for the first time investigated by immunohistochemistry and fluorescence in situ hybridization (FISH) the prevalence of cyclin D3 abnormalities in gastrointestinal stromal tumors (GISTs), comparing the results with traditional pathological characteristics, p27 immunoreactivity (IR), and Ki-67 labeling index (LI). All the tumors showed nuclear cyclin D3 IR, with a percentage of immunostained neoplastic cells ranging from 10 to $95 \%$ (mean, $67.3 \pm 22.9 \%$ ). In $4(40 \%)$ of the 10 cases analyzed by FISH, cyclin $D 3$ extrasignals were detected. Cohybridization with probes specific for the centromeric region and the long arm of chromosome 6 indicated trisomy in one case, whereas in the remaining three cases the pattern was highly suggestive for the occurrence of an isochromosome 6p. There was no association between the cyclin D3 gene copy number and IR for the encoded protein. Cyclin D3 IR was positively associated with p27 IR $(P=.004)$ but not with Ki-67 LI or tumor malignant potential. On the contrary, p27 IR was inversely associated with Ki-67 LI $(P=.004)$ and was more prevalent in tumors of low or intermediate malig-

Copyright @ 2003 by The United States and Canadian Academy of Pathology, Inc.

VOL. 16, NO. 9, P. 886, 2003 Printed in the U.S.A.

Date of acceptance: January 8, 2003.

The first two authors contributed equally to the work.

This work was supported by grants from the Associazione Italiana Ricerca sul Cancro (AN and GV).

Address reprint requests to: Giuseppe Viale, M.D., Division of Pathology and Laboratory Medicine, European Institute of Oncology, via Ripamonti 435, 20141, Milan, Italy; fax: 39-02-57489417; e-mail: giuseppe.viale@ieo.it.

DOI: 10.1097/01.MP.0000085026.38856.B9 nant potential, though at a borderline level of statistical significance $(P=.066)$ only. These data suggest that cyclin D3 expression in GISTs is independent of gene amplification and that this protein may be involved in the pathogenesis of GISTs by counteracting the inhibitory activities of p27.

KEY WORDS: Cyclin D3, FISH, Gastrointestinal stromal tumors, Immunohistochemistry.

Mod Pathol 2003;16(9):886-892

Cyclin D3 plays a pivotal role in tightly controlling the physiological progression from the G1 to the $\mathrm{S}$ phase of the cell cycle. After assembling with the cyclin-dependent kinases (cdk) 4 and 6, cyclin D3 is capable of phosphorylating the retinoblastoma $(\mathrm{Rb})$ gene product, eventually promoting the entry to the S-phase (1). In addition to phosphorylating Rb, cyclin D3 also promotes transition to the S phase by sequestering p27 (2).

Cyclin D3 maps to the 6p21 locus and may be deregulated in a fraction of hematopoietic disorders as a consequence of the $t(6 ; 14)(\mathrm{p} 21.1 ; \mathrm{q} 32.3)$ translocation that juxtaposes the cyclin D3 gene to the 3 ' IgH sequences $(3,4)$. Moreover, amplification of the cyclin D3 gene has been documented in sporadic cases of malignant gliomas (5) and nonHodgkin's lymphomas $(6,7)$. An abnormal expression of cyclin D3 has been documented in a variety of human malignancies (8-10). With regard to soft tissue tumors, immunoreactivity (IR) for cyclin D3 has been found in approximately $20 \%$ of leiomyosarcomas (11) and liposarcomas (12).

Gastrointestinal stromal tumors (GISTs) represent the commonest mesenchymal neoplasm of the gastrointestinal tract, accounting for approximately $15 \%$ of all soft tissue tumors. Recent data suggest that abnormalities of the genes controlling the cell 
cycle progression may be involved in the pathogenesis and progression of GISTs $(13,14)$. In this study, we first evaluated by fluorescence in situ hybridization (FISH) and immunohistochemistry the prevalence of cyclin D3 abnormalities in a wellcharacterized series of GISTs. The results were compared with traditional pathologic characteristics, p27 IR, and Ki-67 labeling index.

\section{MATERIALS AND METHODS}

\section{Patients and Samples}

Twenty-one consecutive surgically treated primitive GISTs were retrieved from the files of the Division of Pathology and Laboratory Medicine of the European Institute of Oncology. The clinicopathological features of the patients included in the study are shown in Table 1. All the tumors exhibited definite cytoplasmic IR for CD117 (c-kit). There were $13(61.9 \%)$ men and 8 (38.1\%) women, with a mean age of 56 years (range, 36-71 y). Sites of involvement were stomach (10 cases, $47.6 \%$ ), ileum (5, $23.8 \%$ ), and colon $(6,28.6 \%)$. According to the recommendations recently proposed by Fletcher et al. (15), the tumors were reclassified as being of low (3 cases, $14.3 \%)$, intermediate $(4,19 \%)$, and high malignant potential $(14,66.7 \%)$.

\section{Immunohistochemistry}

Immunoreactivity for cyclin D3, p27, and Ki-67 antigen was evaluated by means of the avidinbiotin peroxidase complex (ABC) method, using the 3,3'-diaminobenzidine tetrahydrochloride chromogen, as described elsewhere (16). Immunostaining was performed using an automated immunostainer (Autostainer; DAKO, Glostrup, Denmark). For antigen retrieval, the slides were placed in $0.01 \mathrm{M}$ EDTA buffer at pH 8.0 (for cyclin D3 and Ki-67), or $0.1 \mathrm{M}$ citrate buffer at $\mathrm{pH} 6.0$ (for p27), and underwent three 4-minute (for cyclin D3 and Ki-67) or two 5 -minute (for p27) cycles at $90^{\circ} \mathrm{C}$ in a microwave oven operating at $780 \mathrm{~W}$. The sections were immunostained with the following monoclonal antibodies: DCS22 (Novocastra, Newcastle upon Tyne, UK, at a working dilution of 1:40) for cyclin D3, Kip-1 for p27 (Transduction Laboratories, Lexington, UK; 1:600), and Mib-1 for Ki-67 (DAKO; 1:200). At least 500 neoplastic cells were evaluated at $400 \times$ magnification without knowledge of the genetic and clinicopathological data, and the percentage of neoplastic cells showing definite nuclear staining was recorded. Built-in positive controls were endothelial and ganglion cells for cyclin D3; small lymphocytes, plasma cells, and endothelial cells for p27; and epithelial cells of the gastric and intestinal glands for the three antibodies. Negative-control sections were incubated with nonimmune mouse serum in place of the specific primary antibodies.

\section{FISH Analysis}

In the 10 cases analyzed, nuclei were extracted from two $50-\mu \mathrm{m}$-thick sections of formalin-fixed and paraffin-embedded samples. Briefly, the sections were dewaxed, rehydrated, and digested in a $0.5 \%$ pepsin solution at $37^{\circ} \mathrm{C}$. The samples were then filtered through a $30-\mu \mathrm{m}$ mesh nylon filter. The nuclei were pelleted by centrifugation at 1500 rpm for 10 minutes and resuspended in PBS, then

TABLE 1. Clinicopathologic Characteristics of the Patients Included in the Study Grouped According to the Malignant Potential

\begin{tabular}{|c|c|c|c|c|c|c|c|c|}
\hline Case & Malignant Potential & Age & Gender & Site & Ki-67 LI (\%) & Cyclin D3 IR (\%) & Cyclin D3 Extrasignals & p27 IR (\%) \\
\hline IEO1 & 3 & 53 & $\mathrm{M}$ & Colon & 15 & 45 & $\mathrm{Nd}$ & 70 \\
\hline IEO2 & 3 & 54 & $\mathrm{~F}$ & Ileum & 15 & 90 & None & 80 \\
\hline IEO3 & 3 & 58 & $\mathrm{~F}$ & Stomach & 11 & 80 & None & 80 \\
\hline IEO4 & 3 & 57 & $\mathrm{M}$ & Stomach & 14 & 85 & None & 95 \\
\hline IEO6 & 3 & 58 & $\mathrm{~F}$ & Ileum & 35 & 60 & None & 75 \\
\hline IEO8 & 3 & 50 & $\mathrm{M}$ & Colon & 21 & 10 & $\mathrm{Nd}$ & 50 \\
\hline IEO9 & 3 & 46 & $\mathrm{M}$ & Colon & 12 & 95 & $\mathrm{Nd}$ & 70 \\
\hline IEO10 & 3 & 66 & $\mathrm{M}$ & Colon & 16 & 80 & None & 60 \\
\hline IEO11 & 3 & 61 & $\mathrm{M}$ & Stomach & 15 & 90 & $\mathrm{Nd}$ & 80 \\
\hline IEO12 & 3 & 41 & $\mathrm{~F}$ & Stomach & 8 & 70 & $\mathrm{Nd}$ & 90 \\
\hline IEO13 & 3 & 36 & $\mathrm{~F}$ & Colon & 45 & 60 & $\mathrm{Nd}$ & 25 \\
\hline IEO15 & 3 & 60 & $\mathrm{M}$ & Colon & 38 & 70 & Yes & 55 \\
\hline IEO18 & 3 & 54 & $\mathrm{~F}$ & Stomach & 19 & 60 & Yes & 90 \\
\hline IEO20 & 3 & 71 & $\mathrm{M}$ & Ileum & 22 & 30 & $\mathrm{Nd}$ & 50 \\
\hline IEO5 & 2 & 50 & $\mathrm{~F}$ & Esophagus & 4 & 25 & $\mathrm{Nd}$ & 40 \\
\hline IEO16 & 2 & 67 & $\mathrm{~F}$ & Ileum & 9 & 80 & None & 90 \\
\hline IEO17 & 2 & 70 & M & Stomach & 8 & 90 & Yes & 95 \\
\hline IEO19 & 2 & 46 & $\mathrm{M}$ & Stomach & 7 & 75 & $\mathrm{Nd}$ & 95 \\
\hline IEO7 & 1 & 63 & $\mathrm{M}$ & Stomach & 6 & 65 & $\mathrm{Nd}$ & 95 \\
\hline IEO14 & 1 & 55 & $\mathrm{M}$ & Stomach & 4 & 80 & $\mathrm{Nd}$ & 90 \\
\hline IEO21 & 1 & 61 & M & Stomach & 5 & 75 & Yes & 80 \\
\hline
\end{tabular}

$\mathrm{M}=$ male; $\mathrm{F}=$ female; 1 = low malignant potential; 2 = intermediate malignant potential; $3=$ high malignant potential; LI = labeling index; IR = immunoreactivity; $\mathrm{Nd}=$ not done; yes = presence of cyclin D3 extrasignals; none = absence of cyclin D3 extrasignals. 
processed by a cytospin device at $200 \mathrm{rpm}$ for 8 minutes on positively charged slides and treated with $30 \%$ sodium bisulfite (Pretreatment solution; Oncor, Gaithersburg, MD) for 10 minutes, followed by digestion in $250 \mu \mathrm{g} / \mathrm{mL}$ proteinase $\mathrm{K}$ (Oncor) for 10 minutes at $45^{\circ} \mathrm{C}$.

FISH experiments were performed with probes labeled with biotin or with the Cy3 fluorochrome (Amersham, Little Chalfont, UK) by nick translation, as described, with minor modifications (17). Briefly, $600 \mathrm{ng}$ of labeled probe was used for each experiment, and hybridization was performed at $37^{\circ} \mathrm{C}$ in $2 \times \mathrm{SSC}, 50 \%(\mathrm{v} / \mathrm{v})$ formamide, $10 \%(\mathrm{w} / \mathrm{v})$ dextran sulfate, $7.5 \mu \mathrm{g}$ Cot1 DNA (Boehringer Mannheim, Germany), and $3 \mu \mathrm{g}$ of sonicated salmon sperm DNA in a volume of $10 \mu \mathrm{L}$. Posthybridization washing was done three times at $60^{\circ} \mathrm{C}$ in $0.1 \times$ SSC. Biotin-labeled probes were detected using FITC-conjugated avidin (resulting in a green signal; Vector Laboratories, Burlingame, CA); Cy3labeled probes were detected directly as a red signal. Nuclei were counterstained with $4^{\prime}, 6^{\prime}$ diamidino-2-phenylindole dihydrochloride (DAPI) staining. Digital images were obtained using a Leica DMR epifluorescence microscope (Leica Imaging Systems Ltd, Cambridge, UK) equipped with a CCD camera (Cohu Inc., San Diego, CA). FITC-avidin, $\mathrm{Cy} 3$, and DAPI fluorescent signals were detected using specific filters. The images were recorded, pseudocolored, and merged using the QFISH software (Leica) and were finally edited using Adobe Photoshop, Version 6.0 (Adobe Systems, Mountain View, CA).
The cyclin D3 locus was investigated using the PAC clone RP5-973N23 (red signal) (4) in $\geq 200$ nuclei for each case. To assess the occurrence of chromosome 6 aneuploidy in interphase nuclei, the cases with cyclin D3 extrasignals were then separately cohybridized with the following pairs of probes: (1) a chromosome 6 Alpha satellite (green signal, Appligene Oncor) and the probe specific for cyclin D3 locus (red signal); (2) a chromosome 6 Alpha satellite (green signal) and a probe (BAC164C22, red signal) specific for the chromosome region 6q11-12, selected using the NCBI database (www.ncbi.nlm.nih.gov). Figure 1 shows a schematic representation of the locations of the probes used in the study.

Negative controls were uninvolved resection margins from 10 cases of surgically resected gastric adenocarcinoma. At least 200 nuclei were analyzed from these samples, and the percentages of nuclei bearing three or four cyclin D3 extrasignals were 2.5 $\pm 1.46 \%$ and $2 \pm 1.52 \%$, respectively. Accordingly, the cutoff value was settled at $7 \%$ (mean value plus 3 SDs).

\section{RESULTS}

\section{Cyclin D3, p27, and Ki-67 Immunoreactivities}

The immunohistochemical results in the 21 GISTs analyzed are shown in Table 1.

In normal tissues, nuclear cyclin D3 IR was detectable in a minority of epithelial cells of the gastric and intestinal glands, as well as in endothelial
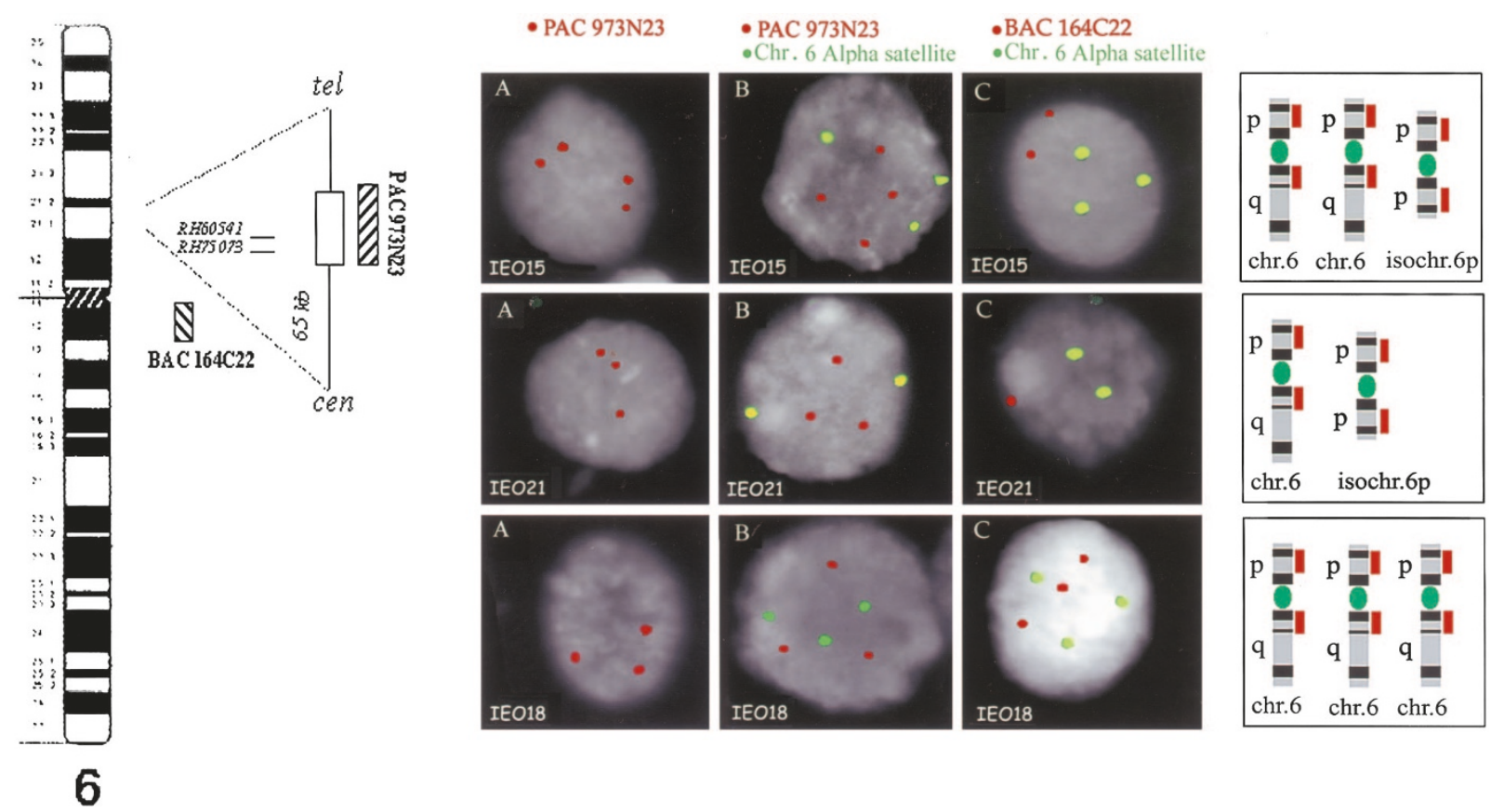

FIGURE 1. Schematic representation of the location of the probes used for the FISH analysis (left panel) and examples of the FISH results in interphase nuclei from three (IEO15, IEO21, and IEO18) different cases of gastrointestinal stromal tumor (central panel). Based on the results of the hybridizations, a schematic representation of the chromosome 6 aneuploidy is given for each tumor (right panel). 
cells and ganglion cells of the Meissner's and Auerbach's plexuses. All the tumors showed nuclear immunoreactivity for cyclin D3, with a prevalence of immunostained neoplastic cells ranging from 10 to 95\% (median, 75\%; mean, $67.3 \%$; standard deviation, $22.9 \%$; $95 \%$ confidence interval, $56.9-77.8 \%$; Fig. 2).

Nuclear p27 IR was detectable in a minority of normal epithelial cells of the gastric and intestinal glands, as well as in small lymphocytes, plasma cells, and endothelial cells. All the GISTs showed nuclear p27 IR, with a percentage of positive neoplastic cells ranging from 25 to $95 \%$ (median, $80 \%$; mean, $74 \pm 20.2$; 95\% CI, 64.8-83.2\%; Fig. 2).

Finally, the Ki-67 LI of the tumors ranged from 4 to $45 \%$ (median, $14 \%$; mean, $15.6 \pm 11.3 \%$; $95 \% \mathrm{CI}$, 10.5-20.8\%; Fig. 2).

\section{Comparison among Cyclin D3, p27, and Ki-67 Immunoreactivities}

A statistically significant direct correlation was found between cyclin D3 and p27 IR $(r=.590, P=$ $.004)$, whereas there was no association between cyclin D3 IR and the Ki-67 LI ( $r=-0.216, P=.347)$. A significant inverse association between p27 IR and the Ki-67 LI ( $r=-0.599, P=.004)$ was also demonstrated.

Comparison between Immunohistochemical and Pathologic Features

There was no association between cyclin D3 or p27 IR or between Ki-67 LI and age $(<56$ y versus $\geq 56$ y; $P=.290, .458$, and .724 , respectively, MannWhitney test $)$ and gender $(P=.884, .364$, and .562 , respectively) of the patients.

Also, there was no correlation between cyclin D3 IR and tumor malignant potential $(P=.914$, MannWhitney test). Tumors with low or intermediate malignant potential, however, showed an higher prevalence of p27 IR (mean, $83.5 \pm 7.5 \%$; 95\% CI, $65.1-100 \%)$ than those with high malignant potential (mean, $68.5 \pm 19.5 \%$; 95\% CI, 57.2-79.8\%), a difference approaching statistical significance $(P=$ .066). There was, however, a significant $(P=.003)$ difference in Ki-67 LI between the tumors with low or intermediate (mean, $6.2 \pm 1.8 \%$; 95\% CI, 4.77.7\%) and high (mean, $20.4 \pm 11.1 \%$; 95\% CI, 14$26.8 \%)$ malignant potential.

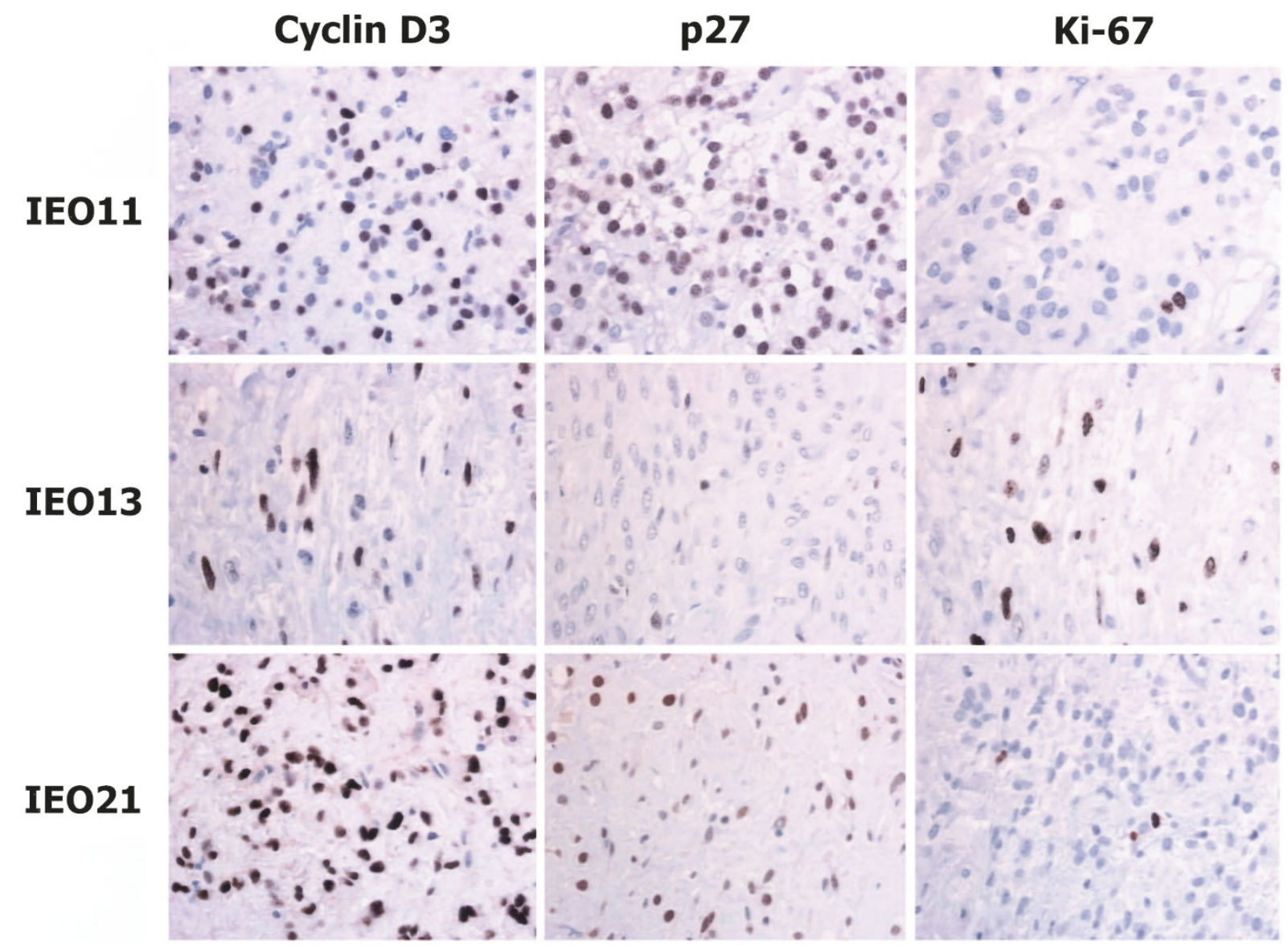

FIGURE 2. Examples of the immunohistochemical results. All the cases show high levels of nuclear cyclin D3 immunoreactivity (IR). Tumors with high nuclear p27 IR are characterized by a low Ki-67 LI and vice versa (200× original magnification; hematoxylin counterstain). 


\section{FISH Analysis}

The results of the FISH analysis are shown in Table 1. In 4 (IEO15, IEO17, IEO18, and IEO21) of the 10 cases analyzed (40\%), cyclin D3 gene extrasignals were observed (Fig. 1). The mean percentage of nuclei with cyclin D3 extrasignals was $50.6 \%$ (range, 10.5-90\%). In particular, there were two cases (IEO18 and IEO21) harboring three signals of the cyclin D3 gene and two cases (IEO15 and IEO17) with either three (in $74 \%$ and $7 \%$ of the cells, respectively) and four signals (in $16 \%$ and $3.5 \%$ of the cells, respectively). Cyclin D3 extrasignals were found in two of the three cases of low or intermediate malignant potential and in two of the seven cases of high malignant potential $(P=.500$, Fisher's exact test) analyzed by FISH.

All the cases bearing cyclin D3 extrasignals were cohybridized with an alphoid probe specific for the centromeric region of chromosome 6 . Two signals of the centromeric region and three signals of cyclin D3 were detected in Case IEO21, and three signals of either the centromeric region and cyclin D3 in Case IEO18 (Fig. 1). The last two cases (IEO15 and IEO17) showed either three signals of the centromeric region and four of cyclin D3 or two signals of the centromeric region and three signals of cyclin D3.

Finally, the cohybridization with probes specific for the 6q11-12 and the chromosome 6 centromeric regions documented one signal of 6q11-12 and two signals of the alphoid probe in Case IEO21 and three signals of both 6q11-12 and alphoid probe in Case IEO18 (Fig. 1). The last two cases (IEO15 and IEO17) had nuclei with either two signals of the 6q11-12 and three signals of the centromeric region, and one signal of the 6q11-12 and two signals of the centromeric region.

In summary, these results indicate the occurrence of trisomy 6 in Case IEO18 and a putative isochromosome involving the short arm of chromosome 6 in Cases IEO15, IEO17, and IEO21 (Fig. 1).

\section{Comparison between Immunohistochemical and FISH Analyses}

The mean rate of cyclin D3 IR was $73.7 \pm 12.5 \%$ (95\% CI, 53.8-93.6\%) in the four cases with cyclin D3 extrasignals and $79.1 \pm 10.2 \%(95 \% \mathrm{CI}, 68.4-$ $89.8 \%)$ in the remaining six cases ( $P=.542$, MannWhitney test). No association was ascertained either between the results of the FISH analysis and p27 IR $(P=.914)$ or Ki-67 LI $(P=.914)$.

\section{DISCUSSION}

In this study, we analyzed for the first time the prevalence of cyclin D3 abnormalities in a wellcharacterized series of GISTs.
We found extrasignals of the cyclin D3 gene in $40 \%$ of the cases analyzed by FISH. The cohybridization with probes specific for the centromeric region and the long arm of chromosome 6 revealed that one case harbored an apparent trisomy of chromosome 6 , whereas the remaining three cases showed a pattern highly suggestive for the presence of an isochromosome $6 \mathrm{p}$. The occurrence of an isochromosome 6 has been reported previously in retinoblastomas (18) and non-Hodgkin's lymphomas (19). In the 37 GISTs investigated by traditional cytogenetic approaches, loss of chromosome 14 and/or 22 was the commonest abnormality, whereas the only reported change of chromosome 6 was chromosome loss in approximately $10 \%$ of the cases (20-23). Nevertheless, Debiec-Rychter et al. (24) reported that almost $10 \%$ of the GISTs analyzed by FISH showed additional signals of the centromeric region of chromosome 6. Likewise, El-Rifai et al. (25), using comparative genomic hybridization, documented gains or high levels of amplification of the $6 \mathrm{p}$ region in $5 \%$ of the tumors analyzed. Interestingly, gain of $6 \mathrm{p} 1 / \mathrm{p} 2$ has been reported recently to be an independent predictor of poor survival in a series of 151 high-grade soft tissue sarcomas analyzed by chromosomal binding (26). Although we did not find any association between the occurrence of $6 \mathrm{p} 21$ extrasignals and tumor malignant potential, the above data suggest verification of the clinical relevance of gain of material from the short arm of chromosome 6 in larger series of GISTs.

The mechanisms by which cyclin D3 may be deregulated in human tumors have not yet been fully elucidated. The $\mathrm{t}(6 ; 14)$ translocation, which juxtaposes the cyclin D3 to the 3' IgH sequences, has been detected in a minority of plasma cell myeloma (3), whereas cyclin D3 gene amplification has been documented in sporadic cases of malignant glioma (5) and non-Hodgkin's lymphoma $(6,7)$. Nevertheless, cyclin D3 expression has been reported in a variety of malignancies with a much higher prevalence than gene alterations (8-12). Likewise, we found a high prevalence of cyclin D3 IR in the majority of the cases analyzed, irrespective of the occurrence of cyclin D3 gene extrasignals. Cyclin D3 IR is significantly higher in GISTs than previously reported in other types of soft tissue tumors. In particular, cyclin D3 IR has been detected in only $14 \%$ of liposarcomas (11) and in $21 \%$ of leiomyosarcomas (12). Although this discrepancy may be at least in part justified by the different anti-cyclin D3 antibodies used, the data lead to the hypothesis that cyclin D3 deregulation may be involved in the pathogenesis of GISTs. Because cyclin D3 immunoreactivity was not associated with the occurrence of gene extrasignals in the 10 cases analyzed, we also speculate that, similarly to other malignancies (812), cyclin D3 deregulation may occur in GISTs as a 
result of epigenetic mechanisms. In keeping with recent findings in aggressive B-cell lymphomas (27, 28), we observed a direct correlation between cyclin D3 and p27 IR, also in GISTs. p27 is capable of blocking progression from the G1 to the $\mathrm{S}$ phase of the cell cycle by binding cyclin E-cdk2 and cyclin A-cdk2 (29). Counteracting the p27 functions is a common way of escape from the physiological growth control in human tumors, and this may be achieved by promoting p27 ubiquitin proteasome degradation or by sequestering it in cyclins $\mathrm{D} / \mathrm{cdk}$ or cyclin E/cdk complexes. D-type cyclins and cdk4 competitively bind and down-regulate the activity of p27 and may thereby act on a pathway that reverses cdk2 inhibition and enables G1 progression (30). The present data allow speculation that high levels of cyclin D3 in GISTs could lead to p27 stabilization and functional inactivation, which in turn may contribute to an uncontrolled tumor growth. We did not find any association between cyclin D3 IR and the pathological features analyzed. On the contrary, however, we document a significant inverse association between p27 IR and Ki-67 LI. Moreover, p27 IR decreased in GISTs of high malignant potential, although this trend only approached statistical significance, possibly because of the small series of cases analyzed. In this regard, it should also be underlined that in our series there were only three cases of low malignant potential. Down-regulation of p27 due to ubiquitin-mediated proteasome degradation has been reported to be associated with a worse prognosis in different tumor types, independent of traditional pathologic parameters (31). Taken together, these data suggest that it may be of interest to further investigate the clinical relevance of p27 IR in larger series of GIST patients with adequate follow-up.

\section{REFERENCES}

1. Malumbres M, Barbacid M. To cycle or not to cycle: a critical decision in cancer. Nat Rev Cancer 2001;1:222-31.

2. Sherr CJ, Roberts JM. CDK inhibitors: positive and negative regulators of $\mathrm{G}_{1}$-phase progression. Genes Dev 1999;13:150112.

3. Shaughnessy J Jr, Gabrea A, Qi Y, Brents L, Zhan F, Tian E, et al. Cyclin D3 at 6p21 is dysregulated by recurrent chromosomal translocations to immunoglobulin loci in multiple myeloma. Blood 2001;98:217-23.

4. Sonoki T, Harder L, Horsman DE, Karran L, Taniguchi I, Willis TG, et al. Cyclin D3 is a target gene of $\mathrm{t}(6 ; 14)(\mathrm{p} 21.1$; q32.3) of mature B-cell malignancies. Blood 2001;98:283744.

5. Buschges R, Weber RG, Actor B, Lichter P, Collins VP, Reifenberger G. Amplification and expression of cyclin D genes (CCND1, CCND2 and CCND3) in human malignant gliomas. Brain Pathol 1999;9:435-42.

6. Bentz M, Werner CA, Dohner H, Joos S, Barth TF, Siebert R, et al. High incidence of chromosomal imbalances and gene amplifications in the classical follicular variant of follicle center lymphoma. Blood 1996;88:1437-44.
7. Palanisamy N, Abou-Elella AA, Chaganti SR, Houldsworth J, Offit K, Louie DC, et al. Similar patterns of genomic alterations characterize primary mediastinal large-B-cell lymphoma and diffuse large-B-cell lymphoma. Genes Chromosomes Cancer 2002;33:114-22.

8. Doglioni C, Chiarelli C, Macri E, Dei Tos AP, Meggiolaro E, Dalla Palma P, et al. Cyclin D3 expression in normal, reactive and neoplastic tissues. J Pathol 1998;185:159-66.

9. Wong SC, Chan JK, Lee KC, Hsiao WL. Differential expression of $\mathrm{p} 16 / \mathrm{p} 21 / \mathrm{p} 27$ and cyclin D1/D3, and their relationships to cell proliferation, apoptosis, and tumour progression in invasive ductal carcinoma of the breast. J Pathol 2001;194:35-42.

10. Filipits M, Jaeger U, Pohl G, Stranzl T, Simonitsch I, Kaider A, et al. Cyclin D3 is a predictive and prognostic factor in diffuse large B-cell lymphoma. Clin Cancer Res 2002;8:72933.

11. Dei Tos AP, Maestro R, Doglioni C, Piccinin S, Libera DD, Boiocchi M, et al. Tumor suppressor genes and related molecules in leiomyosarcoma. Am J Pathol 1996;148:1037-45.

12. Dei Tos AP, Piccinin S, Doglioni C, Vukosavljevic T, Mentzel T, Boiocchi M, et al. Molecular aberrations of the G1-S checkpoint in myxoid and round cell liposarcoma. Am J Pathol 1997;151:1531-9.

13. Panizo-Santos A, Sola I, Vega F, de Alava E, Lozano MD, Idoate MA, et al. Predicting metastatic risk of gastrointestinal stromal tumors: role of cell proliferation and cell cycle regulatory proteins. Int J Surg Pathol 2000;8:133-44.

14. Al-Bozom IA. p53 expression in gastrointestinal stromal tumors. Pathol Int 2001;51:519-23.

15. Fletcher CD, Berman JJ, Corless C, Gorstein F, Lasota J, Longley BJ, et al. Diagnosis of gastrointestinal stromal tumors: a consensus approach. Hum Pathol 2002;33:459-65.

16. Pruneri G, Pignataro L, Manzotti M, Carboni N, Ronchetti D, Neri A, et al. p63 in laryngeal squamous cell carcinoma: evidence for a role of TA-p63 down-regulation in tumorigenesis and lack of prognostic implications of p63 immunoreactivity. Lab Invest 2002;82:1327-34.

17. Pruneri G, Fabris S, Baldini L, Carboni N, Zagano S, Colombi MA, et al. Immunohistochemical analysis of cyclin D1 shows deregulated expression in multiple myeloma with the $t(11$; 14). Am J Pathol 2000;156:1505-13.

18. Squire J, Phillips RA, Boyce S, Godbout R, Rogers B, Gallie BL. Isochromosome $6 \mathrm{p}$, a unique chromosomal abnormality in retinoblastoma: verification by standard staining techniques, new densitometric methods, and somatic cell hybridization. Hum Genet 1984;66:46-53.

19. White AD, Clark RE, Jacobs A. Isochromosome (6p) in Waldenstrom's macroglobulinemia. Cancer Genet Cytogenet 1992;58:89-91.

20. Bergmann F, Gunawan B, Hermanns B, Hoer J, Schumpelick V, Fuzesi L. Cytogenetic and morphologic characteristics of gastrointestinal stromal tumors. Recurrent rearrangement of chromosome 1 and losses of chromosomes 14 and 22 as common anomalies. Verh Dtsch Ges Pathol 1998;82:275-8.

21. Marci V, Casorzo L, Sarotto I, Dogliani N, Milazzo MG, Risio M. Gastrointestinal stromal tumor, uncommitted type, with monosomies 14 and 22 as the only chromosomal abnormalities. Cancer Genet Cytogenet 1998;102:135-8.

22. Breiner JA, Meis-Kindblom J, Kindblom LG, McComb E, Liu $\mathrm{J}$, Nelson M, et al. Loss of $14 \mathrm{q}$ and $22 \mathrm{q}$ in gastrointestinal stromal tumors (pacemaker cell tumors). Cancer Genet Cytogenet 2000;120:111-6.

23. Gunawan B, Bergmann F, Hoer J, Langer C, Schumpelick V, Becker $\mathrm{H}$, et al. Biological and clinical significance of cytogenetic abnormalities in low-risk and high-risk gastrointestinal stromal tumors. Hum Pathol 2002;33:316-21. 
24. Debiec-Rychter M, Lasota J, Sarlomo-Rikala M, Kordek R, Miettinen M. Chromosomal aberrations in malignant gastrointestinal stromal tumors: correlation with c-KIT gene mutation. Cancer Genet Cytogenet 2001;128:24-30.

25. El-Rifai W, Sarlomo-Rikala M, Andersson LC, Knuutila S, Miettinen M. DNA sequence copy number changes in gastrointestinal stromal tumors: tumor progression and prognostic significance. Cancer Res 2000;60:3899-903.

26. Mertens F, Stromberg U, Mandahl N, Cin PD, De Wever I, Fletcher $\mathrm{CD}$, et al. Prognostically important chromosomal aberrations in soft tissue sarcomas: a report of the Chromosomes and Morphology (CHAMP) Study Group. Cancer Res 2002;62:3980-4.

27. Barnouin K, Fredersdorf S, Eddaoudi A, Mittnacht S, Pan LX, $\mathrm{Du} \mathrm{MQ}$, et al. Antiproliferative function of p27kip1 is frequently inhibited in highly malignant Burkitt's lymphoma cells. Oncogene 1999;18:6388-97.
28. Sanchez-Beato M, Camacho FI, Martinez-Montero JC, Saez AI, Villuendas R, Sanchez-Verde L, et al. Anomalous high p27/KIP1 expression in a subset of aggressive B-cell lymphomas is associated with cyclin D3 overexpression. p27/KIP1-cyclin D3 colocalization in tumor cells. Blood 1999;94:765-72.

29. Polyak K, Kato JY, Solomon MJ, Sherr CJ, Massague J, Roberts JM, et al. p7Kip1, a cyclin-Cdk inhibitor, links transforming growth factor-beta and contact inhibition to cell cycle arrest. Genes Dev 1994;8:9-22.

30. Sgambato A, Cittadini A, Faraglia B, Weinstein IB. Multiple functions of p27(Kipl) and its alterations in tumor cells: a review. J Cell Physiol 2000;183:18-27.

31. Lloyd RV, Erickson LA, Jin L, Kulig E, Qian X, Cheville JC, et al. p27kip1: a multifunctional cyclin-dependent kinase inhibitor with prognostic significance in human cancers. Am J Pathol 1999;154:313-23.

\section{Book Review}

\section{Ladanyi M, Gerald WL: Expression Profiling of Human Tumors, Diagnostic and Research Applications, 399 pp, Totowa, NJ, Humana Press, 2003 (\$175.00).}

The study of the expression of genes has become very important in the diagnosis and therapeutic approach of tumors. The aim of this book is to help understand the technical aspects and applications of gene profiling in human tumors. Given the evolving nature of these issues and the information overload, this book constitutes a welcome introduction and comprehensive review of this important topic.

The book consists of 20 chapters that cover in great detail the technical, clinical, and research aspects of gene expression in human tumors. For this purpose, the editors have assembled a group of researchers, all of them experts in their fields, to write the corresponding chapters.

The first chapters are devoted to the basic concepts of gene profiling, followed by chapters that cover each organ system tumor in great detail, providing in-depth technical and clinical information of each tumor type. The two questions of how and why the gene expression profile of tumors should be studied are discussed in each chapter. The impact that these analyses have in the management of patients is emphasized throughout the text. The book also includes practical information in two important issues associated with the gene profiling of tumors: tissue arrays and tumor banking/bioinformatics.

The illustrations in the book, many of them in color, are all of high quality, and the references, listed at the end of each chapter, are up to date.

As with any book with multiple co-authors, there are chapters that are more comprehensive than others with minor overlaps of information between them. However, the editors have done a good job in maintaining consistency throughout the entire book.

The target audience of this excellent book includes all of those interested in the study of cancer, ranging from basic researchers to pathologists, surgeons, and medical oncologists. This book should stimulate the medical community, particularly pathologists, to think and look beyond the pure morphologic aspects of tumors.

\author{
Juan P. Palazzo \\ Thomas Jefferson University \\ Philadelphia, Pennsylvania
}

